\title{
Transverse Flux Permanent Magnet Generator Design and Optimization Using Response Surface Methodology Applied in Direct Drive Variable Speed Wind Turbine System
}

\author{
Javad Soleimani ${ }^{1}$, Abdolhossein Ejlali ${ }^{2}$, Masood Moradkhani ${ }^{3}$ \\ ${ }^{1}$ Electrical Engineering Department of Iran University of Science \& Technology (IUST), Tehran, Iran. \\ ${ }^{2}$ Department of Engineering, Islamic Azad University, Ilam Branch-Center of Mehran, Ilam, Iran. \\ ${ }^{3}$ Department of Electrical Engineering, Ilam Branch, Islamic Azad University, Ilam, Iran.
}

\section{Article Info}

Received Jan 07, 2019

\section{Keyword:}

Transverse Flux Permanent Magnet Generator;

Direct Drive Wind Turbine; Vertical Axis Wind Turbine; RSM Optimization Method; Finite Element Method;

\begin{abstract}
Recently, Transverse Flux Permanent Magnet Generators (TFPMGs) have been proposed as a possible generator in direct drive variable speed wind turbines due to their unique merit. Generally, the quality of output power in these systems is lower than multi stage fixed speed systems, because of removing the gears, so it's important to design these kinds of generators with low ripple and lowest harmful harmonics and cogging torque that is one of the most important terms in increasing the quality of output power of generator. The objective of this paper is introducing a simple design method and optimization of high power TFPMG applied in vertical axis direct drive wind turbine system by lowest possible amplitude of cogging torque and highest possible power factor, efficiency and power density. For this reason an optimum method called combined response surface methodology (RSM) and design of experiment and in order to extract the output values of generator and sensitivity analysis for design and optimization, 3D-Finite element model, was applied. This method has high accuracy and gives us a better insight of generator performance and presents back EMF, cogging torque, flux density and FFT of this TFPMG. This study can help designers in design approach of such generators.
\end{abstract}

\section{Corresponding Author:}

Masood Moradkhani

Department of Electrical Engineering, Ilam Branch, Islamic Azad University, Ilam, Iran.

Email: moradkhani.m@gmail.com

\section{Introduction}

Using renewable energy resources specially wind power during last two decades has increased as worldwide, there are now over two hundred thousand wind turbines operating, with a total nameplate capacity of $282,482 \mathrm{MW}$ as of end 2012. [1,2]

During this time, several wind turbine concepts have been proposed. There are three major topologies of wind turbine systems: fixed-speed wind generators with multi-stage gearbox, variable speed wind generators (with single-stage or multi-stage gearbox) and direct-drive wind generators. [3,4]

Because of several advantages such as removing the gearbox, drive simplification, longevity, high reliability, weight reduction, maintenance cost reduction, higher aggregate efficiency, low level of vibration and noise of the drive train, simplified SCADA structure and better utilization of the available wind power, direct drive variable speed structures in wind power turbines are in attention. $[4,5]$ 
The most important part of these kinds of systems are permanent magnet type generators that have less weight and volume and less cooper and iron losses, more TPC, power factor and efficiency, less mechanical problems and more longevity than their rivals. [5-8]

Among all kinds of permanent magnet synchronous generator types, Transverse Flux Permanent Magnet Generators are the top options for low speed systems and wind turbines because of these merits [4, 5, 9-11]:

- Better cooling condition because of better heat distribution in stator

- Removing the armature reaction effect

- Low copper loss because of having lower end winding in concentrated winding

- Facility in maintenance

- Possibility of being made with a very small pole pitch in comparison with the radial and axial permanent magnet machine. So it can be design by low machine diameter

- High power and torque density (smaller active mass than the other machines to produce the same torque) and low weight because of having hollow rotor core

- Flexibility in geometry design with several kinds of structure

- Increasing the windings space without reducing the available space for the main flux

- Ability to provide a significant cost advantage in active material in comparison with Radial or Axial Flux Permanent magnet machines for small air-gap

Transverse Flux Permanent Magnet machines are the most favorable generators for vertical axis gearless high power turbines because of low rotational speed and having low length and large diameter. Fig. 1 shows the topology of vertical axis wind turbine connected to a PM generator without gearbox [12-14].

Vertical axis turbine systems have save several advantages such as: Insensitivity to wind direction and turbulence, Proper operation in unfavorable wind speeds and storms, facility in maintenance, noise reduction and high output power quality and removing the necklace box [14].

Because of removing the gears, it's important to design these kinds of generators with low ripple and lowest harmful harmonics and cogging torque that is one of the most important terms in increasing the quality of output power of generator $[14,15]$.

Cogging torque in these machines is quite dependent to the geometry and volume of 2 I-Shaped PMs in each pole, the geometry of legs in U-Shaped core and airgap length. TFPMs can be designed with low airgap length for having low leakage flux and high efficiency and power factor but the amplitude of cogging torque and its scheme can be variable and unsuitable. This paper shows the diagram of cogging torque in different airgap length and appropriate.

This paper has classified the TFPMGs structures, and implemented a simple design and optimization method of high power TFPMG applied in vertical axis direct drive wind turbine system by lowest possible amplitude of cogging torque and highest possible power factor, efficiency and power density.

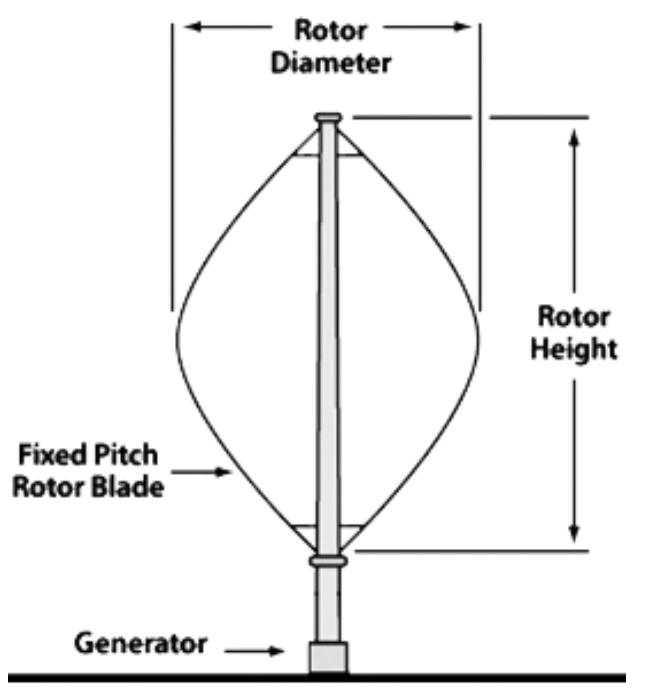

Figure 1. Vertical axis direct drive wind turbine 
For this purpose, a 3D-finite element model (as these machines can be modeled and analyzed just in 3 dimension because of their topologies) and an optimum method called combined response surface methodology (RSM) and design of experiment was applied. This method can achieve excellent performance and low costs by optimizing multiple design variables of TFPM generator [15], and has high level of accuracy and gives a better insight of generator performance.

\section{Structure and Configuration}

- TFPM machines can be classified in the categories below:

- U-shaped core, C-shaped core, E-shaped core and Z-shaped core. (Fig. 2) [4, 5, 11, 16-18]

- Single side, double side or multiple side core. (Fig. 3) [5, 9]

- Inner PM or surface mounted PM structures. (Fig. 4) [5, 9]

- Rayleigh or planar rotor structure. (Fig. 5) [5, 9, 19]

- Double or single piece stator structure. (Fig. 6) $[5,9,11]$

- Active or passive stator structure. (Fig. 7) $[4,5,11]$

- Axial or radial airgap structure. (Fig. 8) $[5,9]$

- Inner rotor or outer rotor topologies. (Fig. 9) $[5,18]$

- Single turn or double turn winding per phase. (Fig. 10) $[5,18,19]$

- Single or triple structure. (Fig. 11) [5, 19, 20]

In addition to these classifications, compound structures with reluctance machines and flux switching can be considered as TFPM machines.

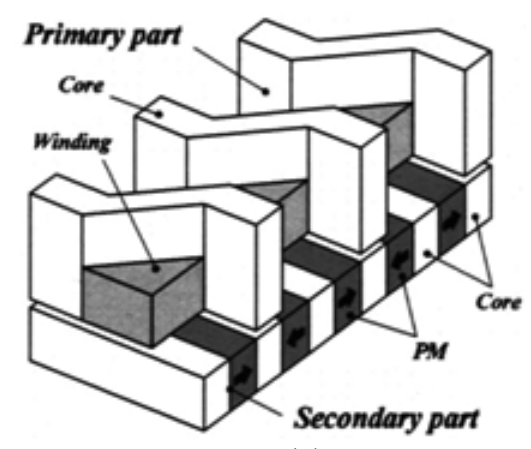

(a)

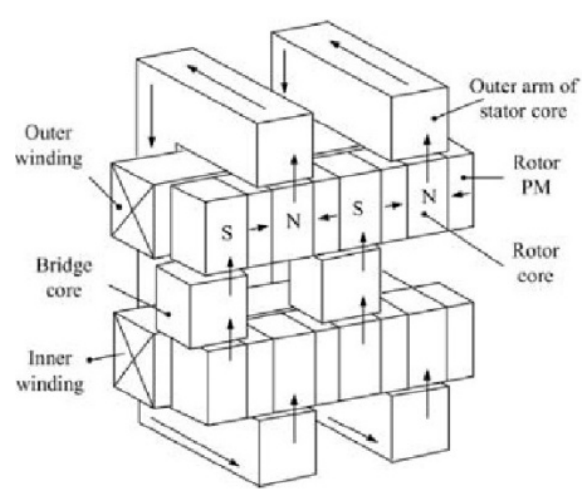

(c)

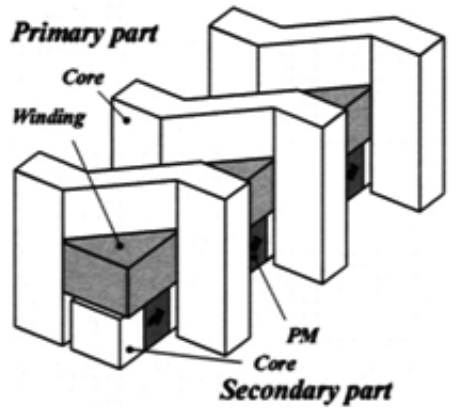

(b)

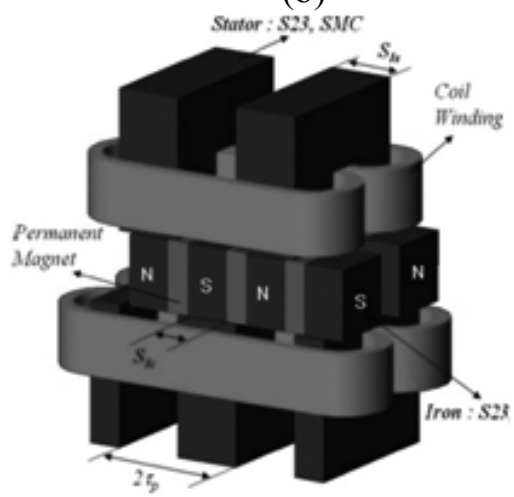

(d)

Figure 2. Transverse Flux Permanent Magnet Machine Classification: (a) U-Shaped Core (stator structure is on the rotor structure) (b) C-Shaped Core (I-Shaped rotor structure is surrounded by Stator Structure) (c) EShaped core (d) Z-Shaped core. E and Z shaped cores are generally complicated to build and high cost. 


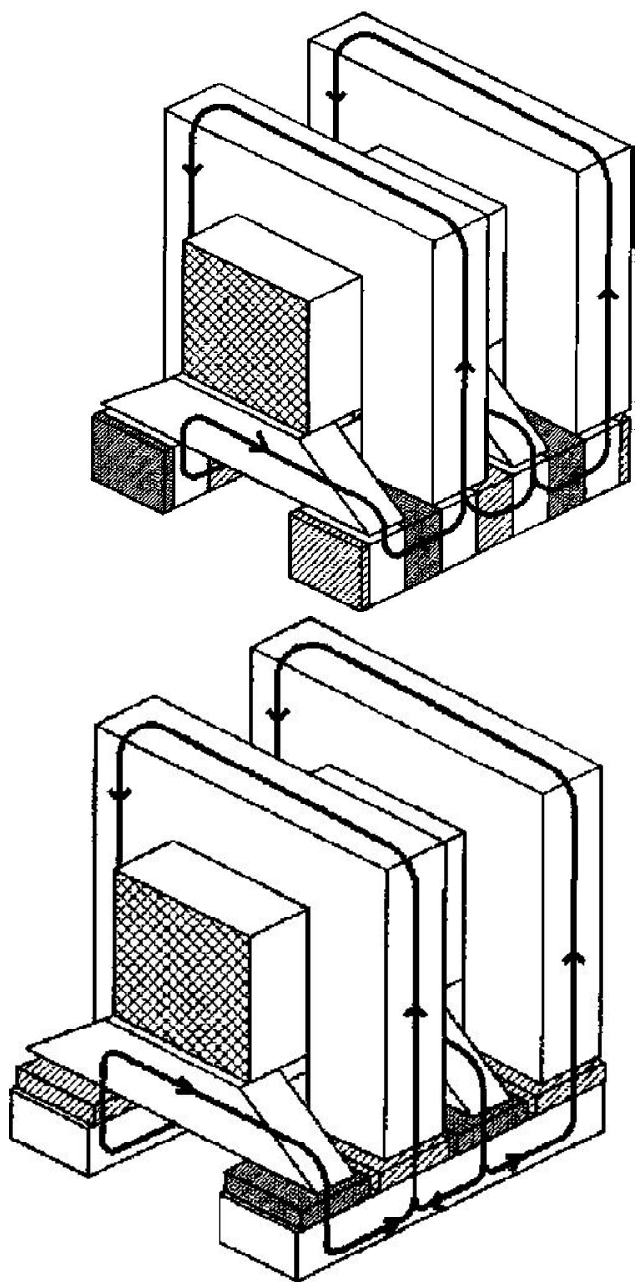

(a)
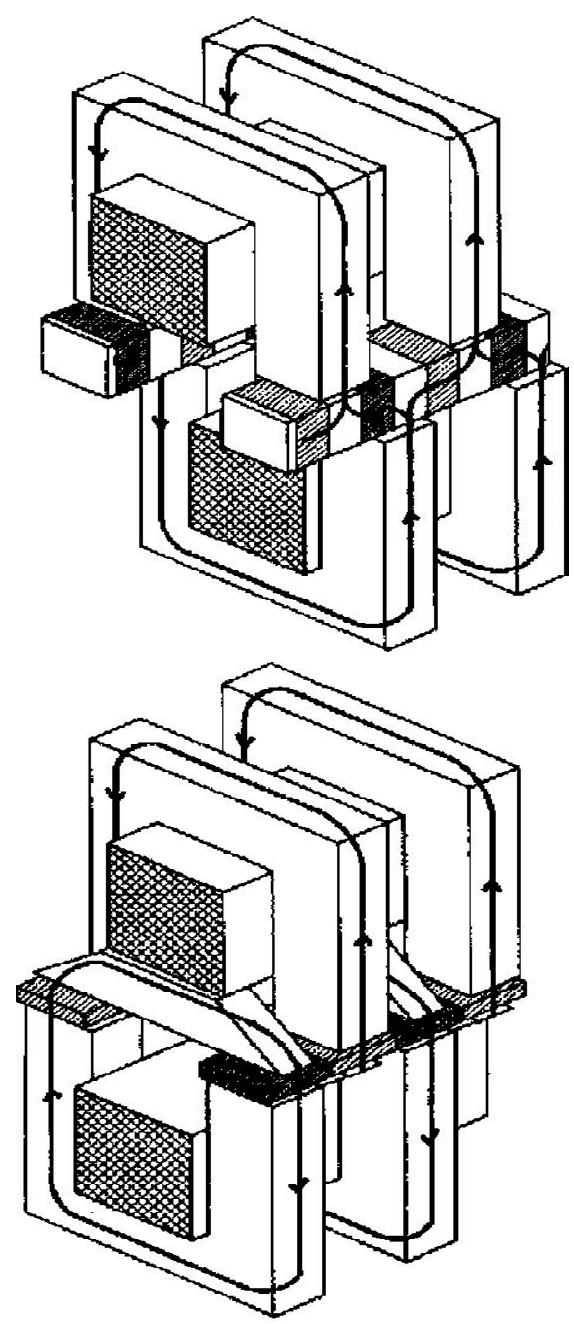

(b)

Figure3. Transverse Flux Permanent Magnet Machine (1 phase, 2 poles) (a) Single side structures (b) Double side structures.

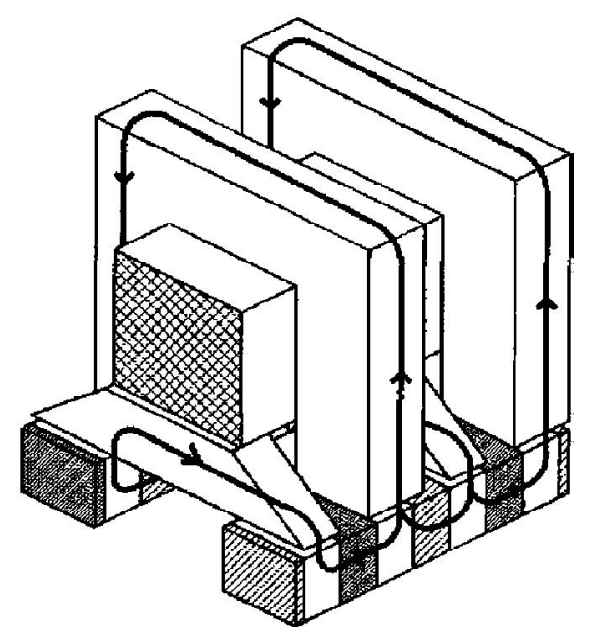

(a)

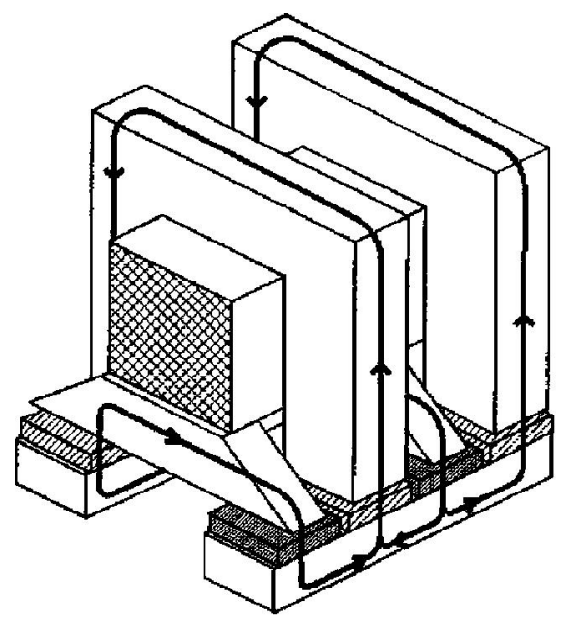

(b)

Figure 4. Transverse Flux Permanent Magnet Machine (1 phase, 2 poles), Difference between Inner PM or surface mounted PM structures. (a) Inner PM used in rotor structure (If the stator is simple these topologies need a bridge in stator structure but if the stator is claw shaped, no need to this additional structure). (b) Surface Mounted PM used in rotor structure (these topologies need a bridge in stator) 


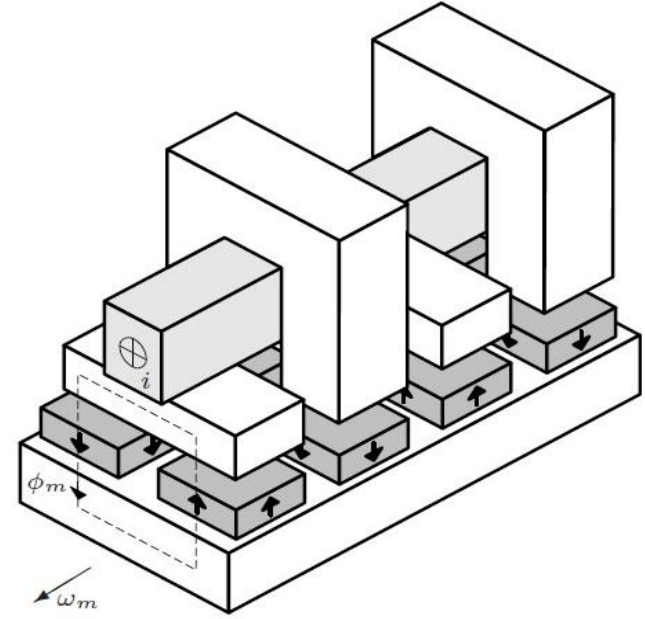

(a)

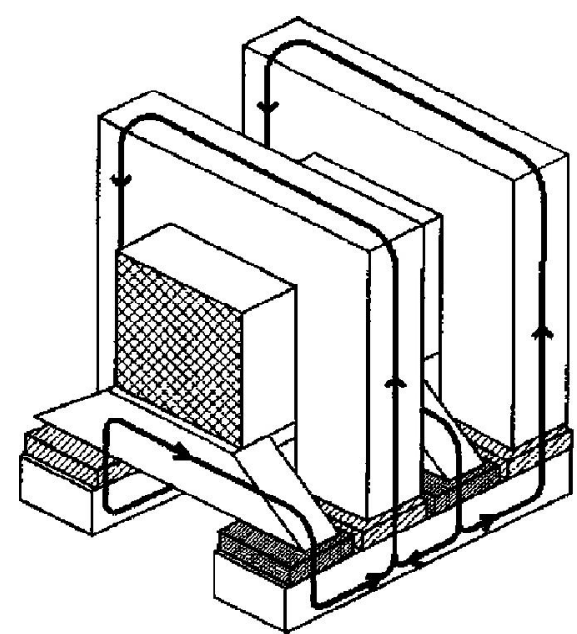

(b)

Figure 5. Transverse flux Permanent Magnet Machine, various rotor topologies: (a) Planar structure. (b) Rayleigh structure.

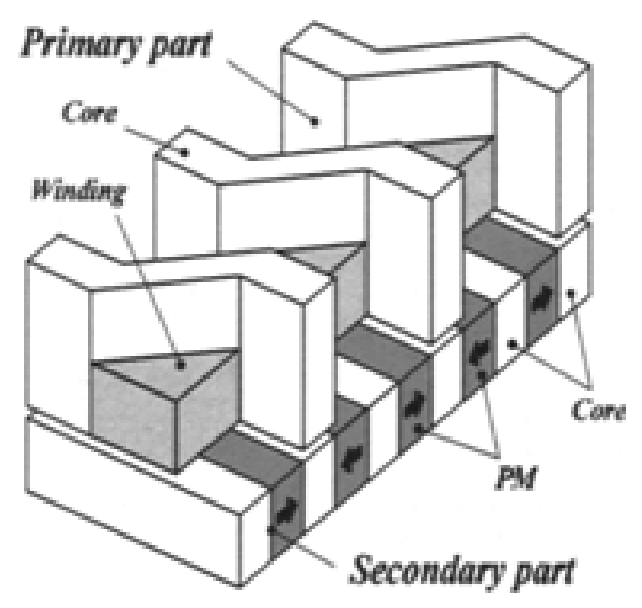

(a)

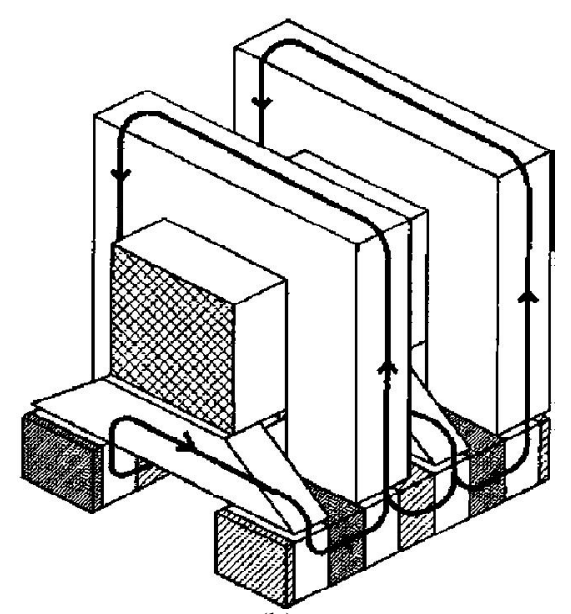

(b)

Figure 6. Transverse flux Permanent Magnet Machine, various stator topologies: (a) Single piece stator structure (b) Double piece stator structure (with bridge).

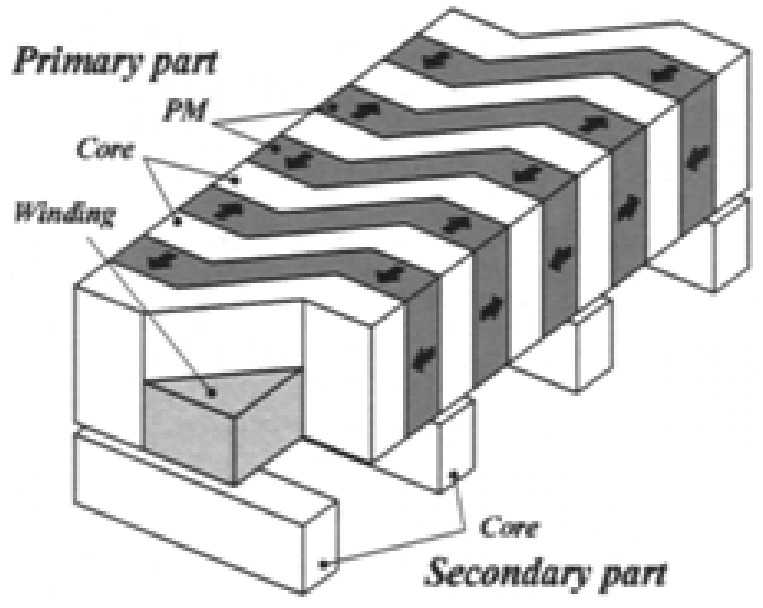

(a)

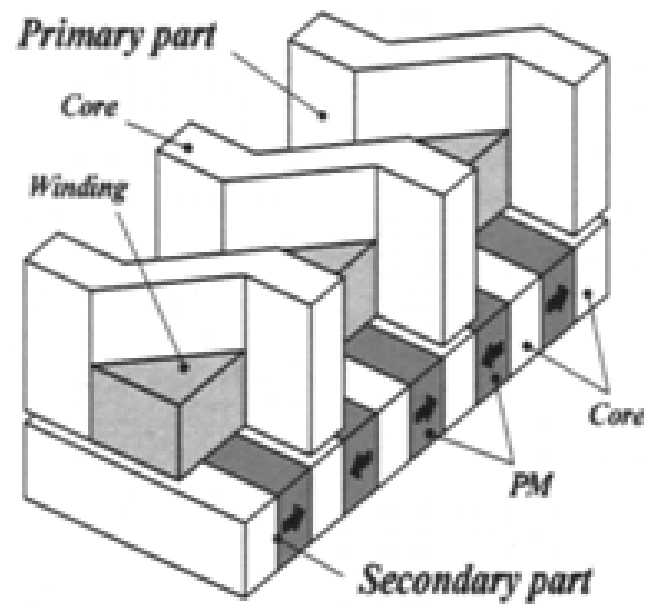

(b)

Figure 7. Transverse flux Permanent Magnet Machine, various stator topologies: (a) Active stator structure. (b) Passive stator structure. 


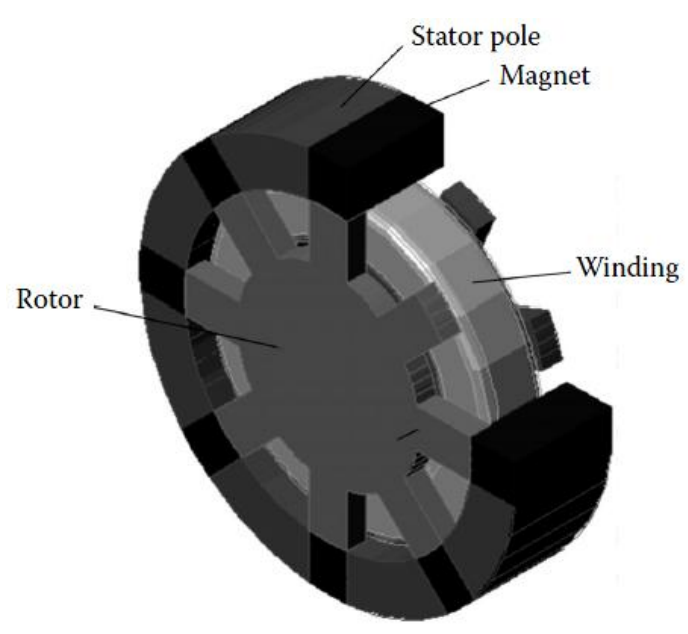

(a)

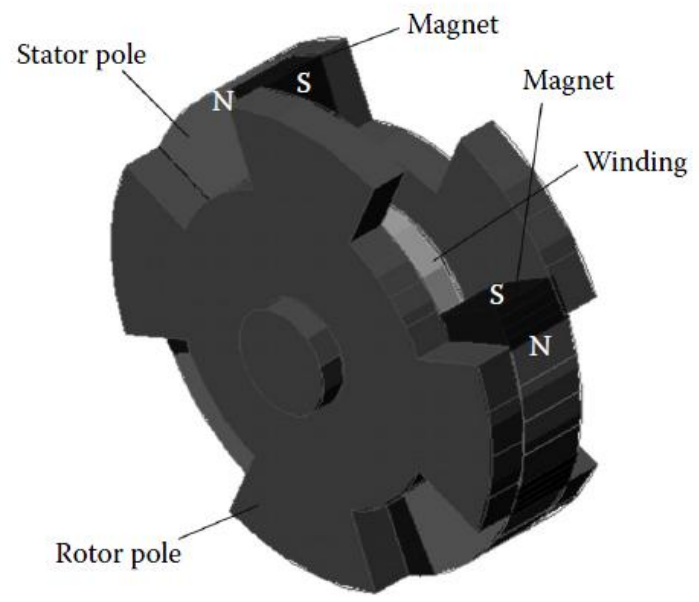

(b)

Fig. 8. Transverse flux Permanent Magnet Machine, The difference between the direction of flux in airgap and the construction: (a) Radial airgap structure. (b) Axial or airgap structure.

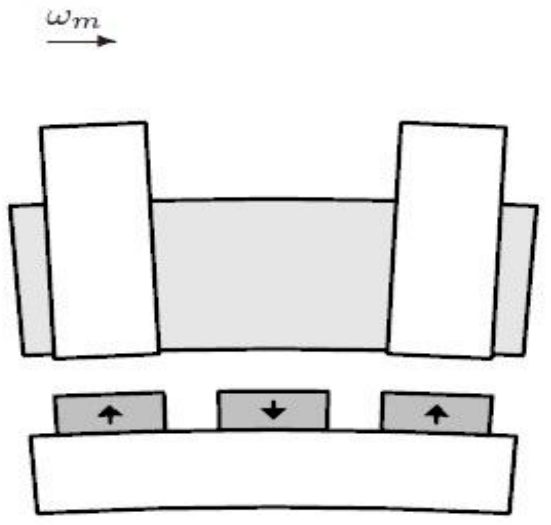

(a)

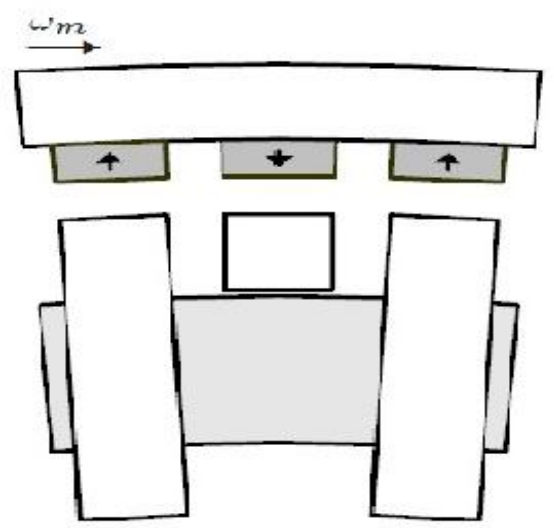

(b)

Fig. 9. Transverse flux Permanent Magnet Machine: (a) Inner rotor topology (b) Outer rotor topology.

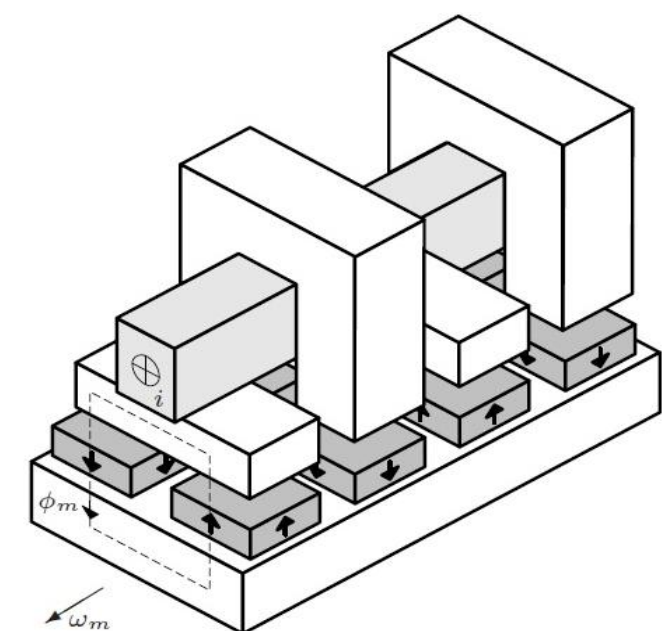

(a)

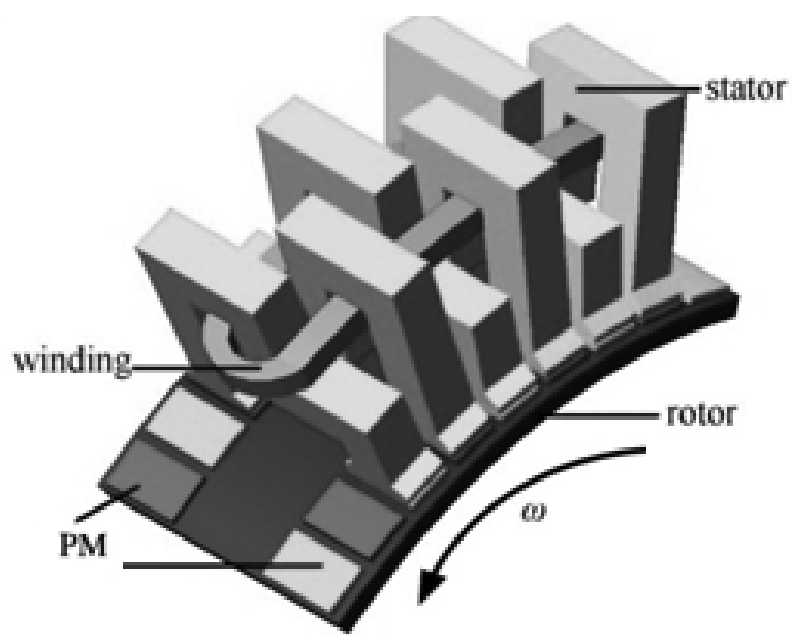

(b)

Figure 10. U-Shaped core Transverse flux Permanent Magnet Machine: (a) Single turn winding per phase. (b) Double turn winding per phase.

Transverse Flux Permanent Magnet Machines are generally single phase, so for building the 3-phase machine, three separated parts should be connected together, but it's possible for Z and E Shaped core topologies and 
the topologies with double winding per phase to build the 3 or more phases in just one part. Fig 11 shows the difference between single or regular triple topologies. Also Fig. 12 shows two possible magnets and windings arrangement methods for connecting the 3 parts of machine (each phase) for building the 3 phase TFPM machine $[5,18,20]$.

As it can be seen, the winding has a three times single phase structure. However, in the case when the flux paths are mixed (Fig. 12.c), the three-phase winding distribution is obtained naturally, as it is usual in the radial-flux machines with concentrated windings. These two possible windings will be referred to as separated and mixed windings, respectively. [18]

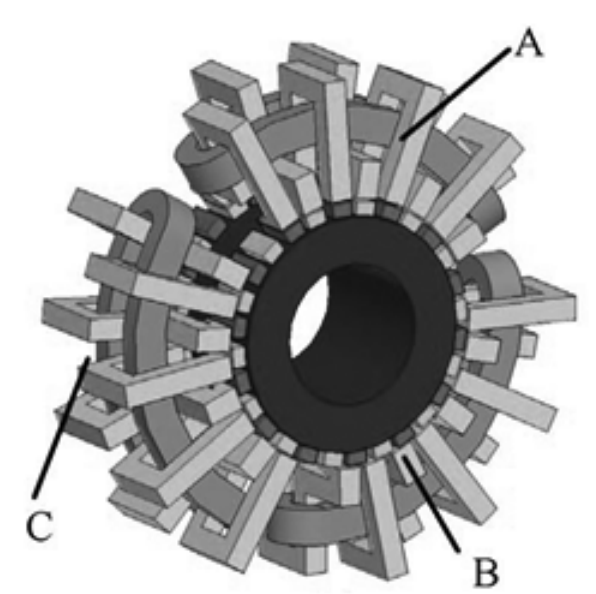

(a)

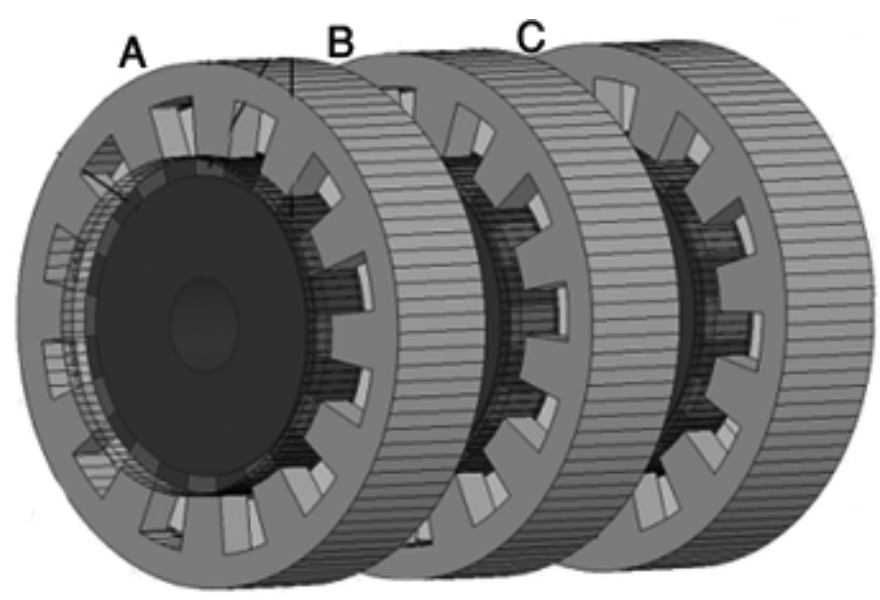

(b)

Figure 11. The difference between single or regular triple topologies: (a) Single part for 3-Phase topology (b) Three parts for 3 phase (one part for each phase) structure.

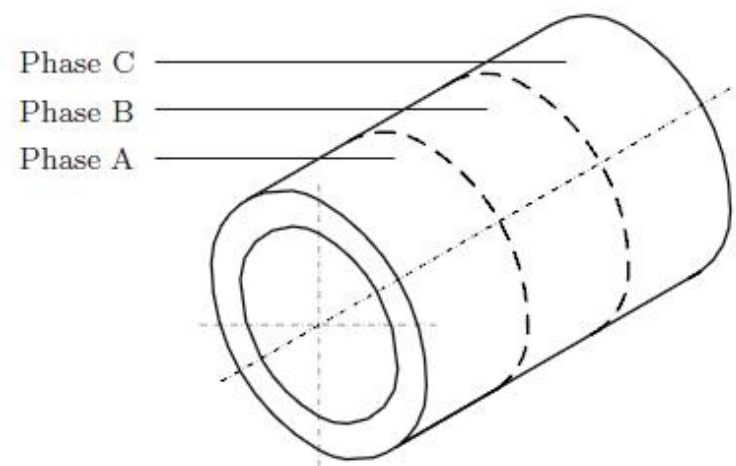

(a)
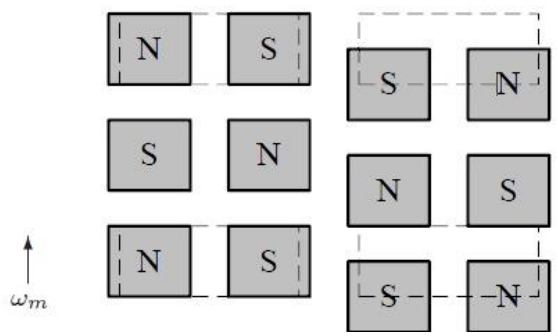

(b)
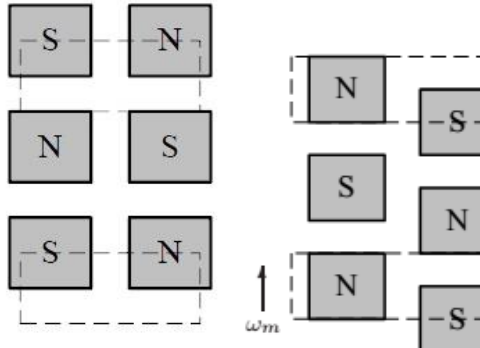

Figure 12. Schematic representation of 3-Phase transverse flux permanent magnet machine, (Three parts for 3 phase structure, one part for each phase): (a) general view of the machine (b) Arrangement of winding in case of separated flux paths (c) Arrangement of windings in case of mixed flux paths. 


\section{Design Method}

The aim of this paper is designing a 3-Phase, claw pole, U-Shaped, Passive Stator, Inner magnet TFPM generator shown in Fig.13. The generator featuresare:13.5 MW (4.5 MW for each phase), 14.4 KV, 15 RPM, 75 pole pairs, $90 \mathrm{KN} / \mathrm{m} 3$ force density (Fd)and 162000 ampere-turn.

Rated torque per phase:

$$
T_{n}=\frac{P_{n}}{\Omega_{n}}=P_{n} / \frac{2 \pi n_{n}}{60}=2.865[M N]
$$

By considering D/L ratio equal to 14 (Generator Dimension Ratio: $\mathrm{k}=14$ ), the primary inner stator diameter is:

$$
D_{g}=\sqrt[3]{\frac{2 . T_{n}}{3 . \pi \cdot \frac{F_{d}}{k}}}=10.402[\mathrm{~m}]
$$

So, Axial length of one phase, ls would be 0.746 . The pole pitch would be:

$$
\tau_{p}=\frac{\pi \cdot D_{g}}{p}=0.218[\mathrm{~m}]
$$

Also the primary airgap length is estimated by:

$$
l_{g}=\frac{0.75 D_{g}}{1000}=7.8[\mathrm{~mm}]
$$

For calculating the dimensions of the rotor, the magnets dimensions should be found firstly. The PM thickness of each pole could be estimated by:

$$
l_{m}=0.3 \cdot \frac{\tau_{p}}{2}=32.65[\mathrm{~mm}]
$$

Then, stator width in each pole would be:

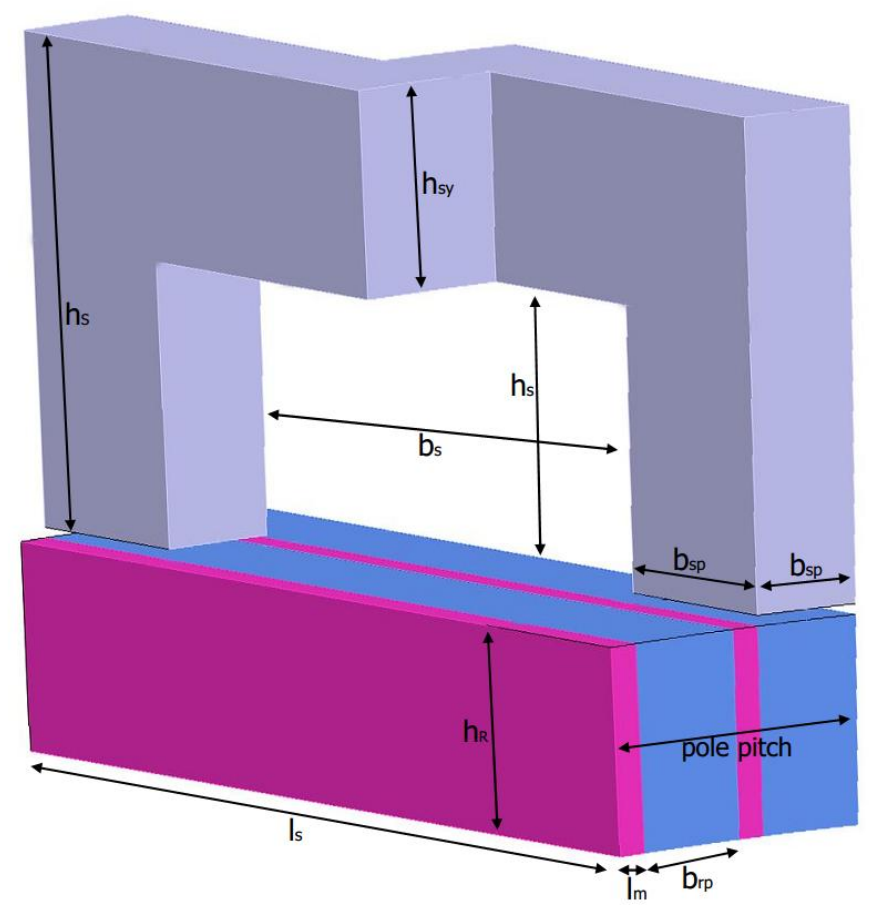

Figure 13. Geometry dimension illustration 3-Phase, claw pole, U-Shaped, Passive Stator, Inner magnet TFPM generator.

$$
b_{s p}=0.8 . \frac{\tau_{p}}{2}=87.1[\mathrm{~mm}]
$$


Rotor width in each pole would be:

$$
b_{r p}=\frac{\tau_{p}}{2}-l_{m}=76.35[\mathrm{~mm}]
$$

By having 162000 ampere-turn and 8.33 kilo volt per phase and ideal power factor estimation for primary design, rated current would be:

$$
I_{n}=\frac{P_{n}}{3 \cdot E}=180[A]
$$

So, number of turns (conductors) per slot is:

$$
N_{c s}=\frac{m m f}{I_{n}}=900[\text { turns }]
$$

By considering 4 (Ampere/mm2) for current density, The cross section of all conductors per slot is:

$$
A_{\text {Cus }}=\frac{N_{c s} \times I_{n}}{J_{s}}=0.0405\left[\mathrm{~m}^{2}\right]
$$

The area of each slot by considering fill factor ratio $=0.5$ would be:

$$
A_{s}=\frac{A_{\text {Cus }}}{k_{\text {sfill }}}=88200 \times 10^{-6}\left[\mathrm{~m}^{2}\right]
$$

By considering stator slot height (hs) $=0.5 *$ stator slot width (bs):

$$
b_{s}=A_{s} / h_{s}=420[\mathrm{~mm}] \quad, \quad h_{s}=210[\mathrm{~mm}]
$$

By considering maximum flux density equal to 1.5 Tesla (it can be considered up to 3 Tesla in regular UShaped core with iron bridge, but it should be less than 1.5 in claw shaped, inner PM topologies because of the direction of flux in the structures), the length of each pole in axial direction is:

$$
l_{s p}=\frac{\sqrt{2} \times E}{(p / 2) \cdot N_{c s l o t} \times B_{p \max } \times \frac{2 \times \pi \times n_{n}}{60} \times b_{p}}=0.143[\mathrm{~m}]
$$

The stator and rotor yokes height would be:

$$
h_{R}=h_{s y} \cong l_{s}=0.143[\mathrm{~m}]
$$

In U-Shaped core TFPM generators it should be $h_{S}>h_{s y}+h_{s}[5,10]$, so the stator height would be 0.233 (m).

So the average radius of winding is:

$$
D_{m}=D_{g}+\frac{1}{2} h_{s}=l_{s p}=5.306[\mathrm{~m}]
$$

The length of each conductor in circumferential direction would be:

$$
L_{\text {con }}=2 \pi D_{m}=33.34[\mathrm{~m}]
$$

By having 900 conductors, the cross section of each conductor is $45 \mathrm{~mm} 2$. (rectangular conductor: $9 * 5 \mathrm{~mm}$ ). The resistance of each phase by considering copper conductors (resistivity $=1.7 \times 10^{-8}$ ) is:

$$
R=\rho \frac{L . N_{c s}}{A_{\text {wire }}}=11.335[\Omega]
$$

Fig. 14. shows the magnetic characteristics diagram of soft magnetic material used in stator core: Initial Relative Permeability is equal to 6000, Saturation Magnetization is 1.6 Tesla and Knee Adjusting Coefficient is 0.3 [14].

Fig. 15. shows the magnetic characteristics diagram of PM used in rotor structure (Nd-Fe-B). For this reason a linear approximation has been used. Remanent Flux Density of this PM is 1.1 Tesla and the Relative Permeability ( $\mu \mathrm{r})$ is 1.0446 [14].

After finding the primary dimension of the generator, by using Finite element simulation and analysis, the exact and optimum dimension of the generator could be found. 


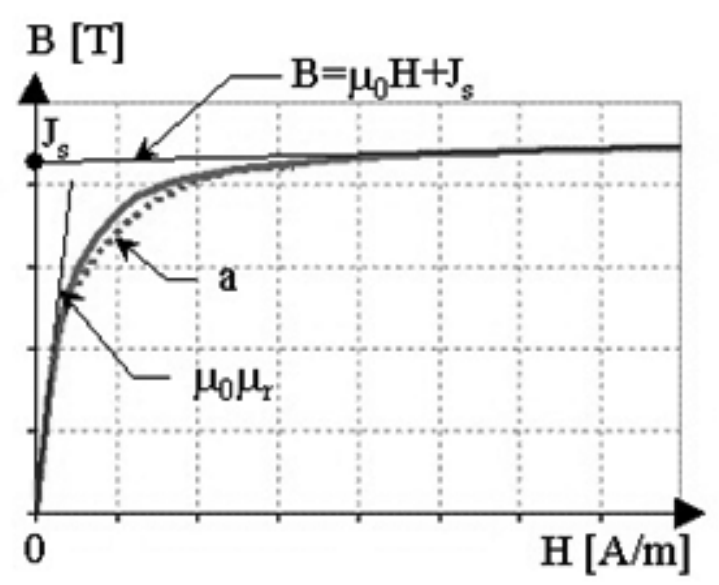

Figure 14. Magnetic characteristics diagram of soft magnetic material used in stator core

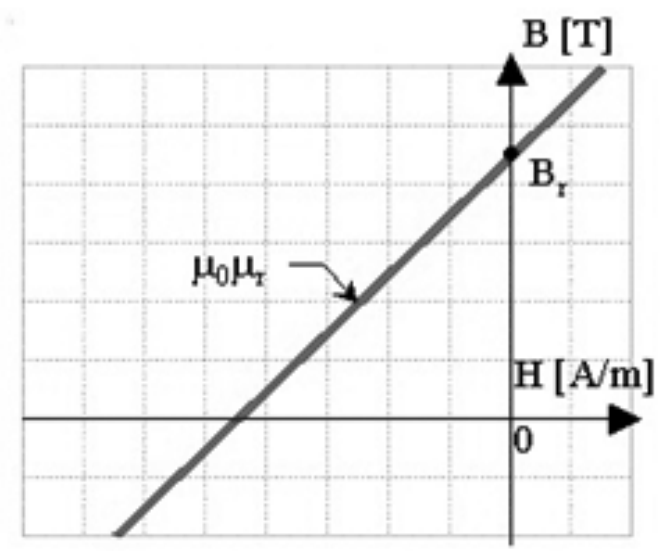

Figure 15. Magnetic characteristics diagram of PM used in rotor structure

\section{FEM Model}

Finite element method (FEM) is the most widely used numerical analysis method in the computer simulations. The FEM does not require a physical prototype production and it can be used to analyze any parts/components of the whole system under certain operating conditions. Also, it permits improvements in the reliability of product by changing the design according to the results of analysis.[21,22]

As it has been mentioned, a 3D-finite element model is implemented in order to simulate the proposed TFPM generator, These machines can be modeled and analyzed just in 3 dimension because of their topologies and the direction of flux in the structures $[5,14]$. This 3D model has high level of accuracy and gives a better insight of generator performance.

In order to have high level of accuracy the mesh diagram is designed manually, in this simulation node congestion is higher around the air gap and center of poles. The total number of nodes is about 103000 per pole per phase, that lead to high level of accuracy, meanwhile, for boundary conditions, the homogenous Dirichlet condition is adopted on the infinite box that encompasses the generator, according to this assumption on infinite box flux distribution is zero.

This simulation is based on circuit coupled model using the phase voltage as input quantity, Fig. 16 shows the circuit coupled model that is used in this study.

It must be noted that one pole of one phase is analyzed because of the magnetic periodicity of the machine, as seen in Fig17 nodes congestion becomes higher near the air gap in order to accurate simulation. Based on FEM model the simulation of the generator is done and output characteristics are extracted. 


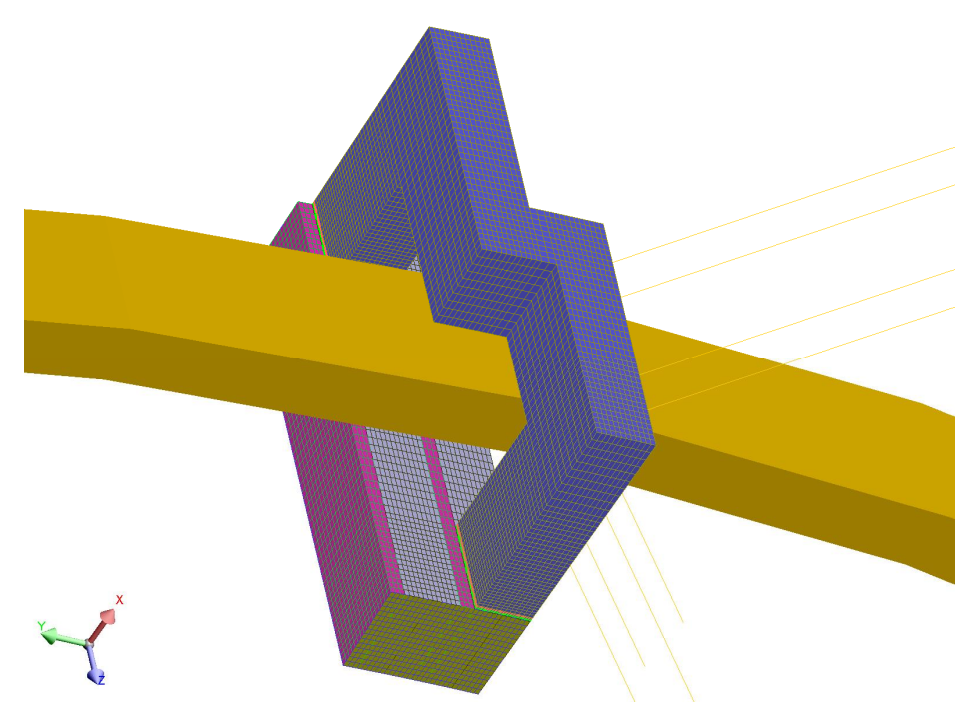

(a)

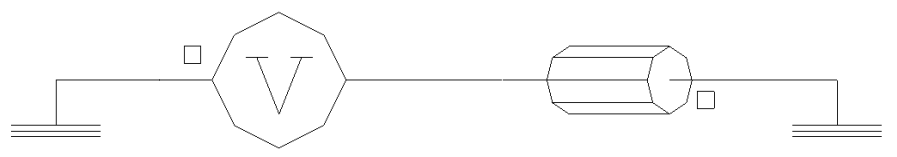

(b)

Figure 16. Circuit coupled model used in this study: (a) Meshed TFPM generator (one pole of one phase) and its winding diagram (b) Circuit coupled model used in simulation for one phase.

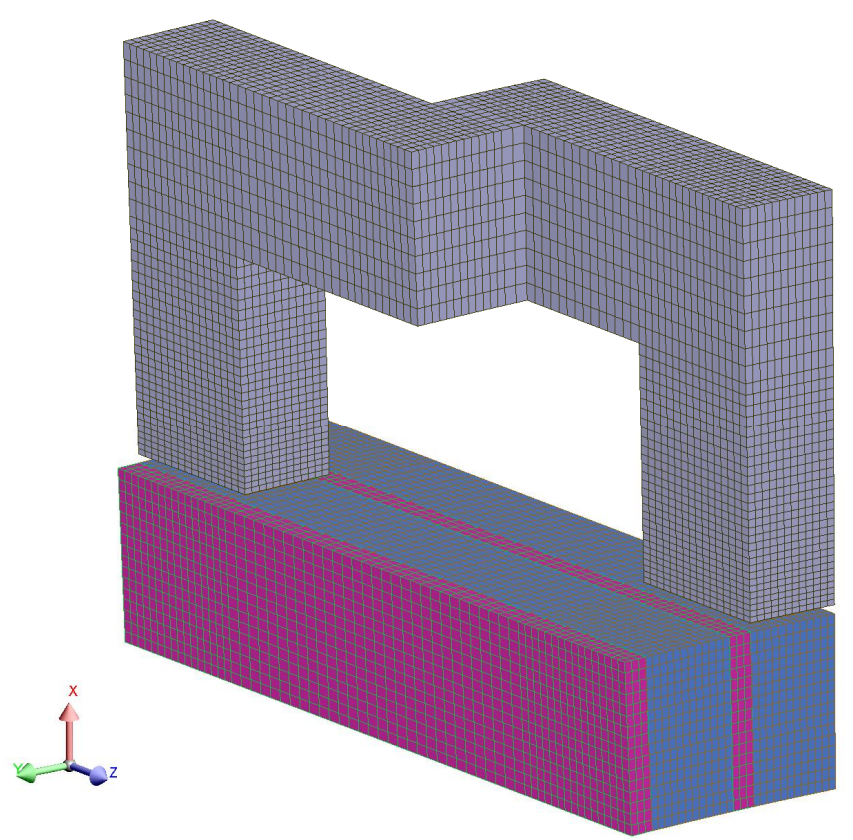

Figure 17. Mesh diagram of simulated machine (One pole of one phase)

\section{Optimization Methodology}

In order to choose an accurate volume of permanent magnet regarding to magnetic circuit that PM material is in, inner diameter of the stator and the airgap length as it has been mentioned, RSM method and design of experiment was applied.

RSM is a set of statistical and mathematical techniques. In RSM, a polynomial model is constructed to represent the relationship between the performance and multiple design variables. The ultimate goal of RSM is to find the best fitted response of the physical system through real experiment or computer simulation [23]. Research and application of RSM as an optimization method have been carried out in many fields [24-26]. As 
a summary, RSM combined with design of experiment is regarded as an ideal method to perform the optimum design for TFM generator [15].

Design of experiment can be regarded as a carefully arranged experiment procedure. The purpose of design of experiment is two-fold. The first is to make the experiment procedure reasonable and can be conducted orderly; and the second is to get adequate and reliable information by minimal number of experiments [15, 2327].

Design of Experiments (DOE) is statistical tool deployed in various types of system, process and product design, development and optimization. It is multipurpose tool that can be used in various situations such as design for comparisons, variable screening, transfer function identification, optimization and robust design. $[28,29]$ Design of Experiments (DOE) mathematical methodology used for planning and conducting experiments as well as analyzing and interpreting data obtained from the experiments. It is a branch of applied statistics that is used for conducting scientific studies of a system, process or product in which input variables (Xs) were manipulated to investigate its effects on measured response variable (Y). [29] Factorial experiments can be design with one, two, three and more factors. Experiments with only one factor are often called simple comparative experiments. [29]

For this methodology, the crucial parameters are: airgap length $(\mathrm{lg}) \mathrm{dv}_{1}, \mathrm{PM}$ thickness $(\mathrm{lm}) \mathrm{dv}_{2}$, and overlap between PM and rotor length in radial direction $(h R)$ and outer rotor radius $\left(D_{r}\right) d v_{3}$, because of their effect on cogging torque and output back EMF of the generator. The overlap is defined as zero when $h_{R}=0$ and it is defined as $100 \%$ when $h_{R}=D_{r}$. Therefore, $d_{1}, d_{2}$, and $d_{2}$ are selected as the design variables to optimize the performance of TFPM generator.

Fig. 18 shows the optimum design process applied in this study using RSM. Table 1 shows the design variables and levels. The design variables in zero level are the values of the initially design. The design variables in $-\alpha$ level and $+\alpha$ level, which are determined by possible values of the three design variables, decide the minimum and maximum respectively [15, 23-27].

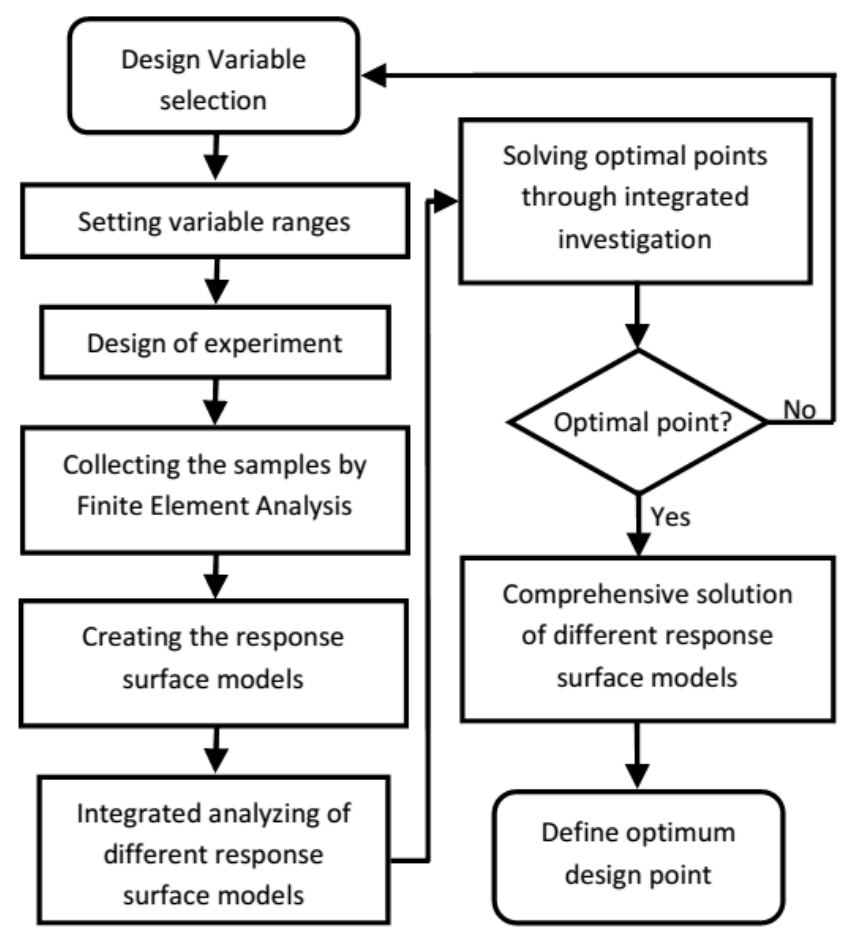

Figure 18. Optimum design process of proposed TFPM generator using RSM

Table. 1 Design variables and levels implemented in RSM

\begin{tabular}{|c|c|c|c|c|c|}
\hline \multirow{2}{*}{ Design variables } & \multicolumn{5}{|c|}{ levels } \\
\cline { 2 - 6 } & $-\alpha$ & -1 & 0 & +1 & $+\alpha$ \\
\hline $\mathrm{dv} 1(\mathrm{~mm})$ & 5.2 & 6.5 & 7.8 & 29.9 & 52 \\
\hline $\mathrm{dv} 2(\mathrm{~mm})$ & 10.875 & 16.325 & 32.65 & 54.375 & 87 \\
\hline $\mathrm{d} 33(\%)$ & 1 & 2 & 3 & 5 & 10 \\
\hline
\end{tabular}


Design of experiment procedure and Response surface methodology has been implemented based on [15], with the three design variables $d v 1, d v 2$ and $d v 3, C C D$ is required to perform 15 experiments, The 3-D finite element model is analyzed for each experiment. Cogging torque and the back EMF are calculated.The main achievements of this method are:

- Finding the accurate dimensions (PM thickness, PM length, hR), outer diameter of the rotor, Dr and the airgap length, lg.

- Reaching to cogging torque less than $5 \%$ of rated torque and suitable waveform for cogging torque and back EMF equal to amplitude of input voltage per phase.

\section{Simulation Result and Discussion}

Based on the above methodology, finite element simulations for the 3-Phase, claw pole, U-Shaped, Passive Stator, Inner magnet TFPM generator has been done in each step. It must be noted that one pole of one phase is analyzed because of the magnetic periodicity of the generator.

Table. 2 shows the varieties of the TFPM generator dimensions after using the optimization method. As it can be observed from the simulation results, this procedure is so effective to find the optimal dimensions of PM, airgap length and the inner diameter of the stator.

Fig. 19-a shows the distribution of flux at rated power. This fig shows the accuracy of assignment of PMs and the correctness of the simulation. Fig. 19-b and c show the isovalues diagram of flux density at rated power. As it can be seen from this figure, flux density at the airgap space and the iron core of the rotor under the stator legs are the highest amount.

Fig. 20 shows the electromagnetic torque of the simulated and optimized machine. This fiqure shows the 2.865 mega Newton of electromagnetic torque per phase as it was our goal by having less than $5 \%$ of torque ripple.

Fig. 21 shows the cogging torque by primary values and optimal values obtained by RSM. As it can be observed from this figures, cogging torque has reached to less than $5 \%$ of rated torque and also its waveform has been improved.

The extracted back EMF for one phase has been shown in Fig. 22. It's obvious that amplitude of back EMF per phase is equal to the amplitude of input voltage per phase.

The output current per phase of simulated TFPM generator by considering the extracted back EMF has been shown is Fig. 23. Also, the harmonic behavior of the output current is shown in Fig. 24. The results shows the authenticity of the proposed method for TFPM generator design and its accuracy.

Table 2. RSM method results

\begin{tabular}{|c|c|c|}
\hline Parameter & Primary value & Optimal value \\
\hline airgap length $\left(\mathrm{l}_{\mathrm{g}}\right)$ & $7.8[\mathrm{~mm}]$ & $40.8[\mathrm{~mm}]$ \\
\hline PM thickness $\left(\mathrm{l}_{\mathrm{m}}\right)$ & $32.65[\mathrm{~mm}]$ & $21.75[\mathrm{~mm}]$ \\
\hline PM and rotor length $\left(\mathrm{h}_{\mathrm{R}}\right)$ & $143[\mathrm{~mm}]$ & $153[\mathrm{~mm}]$ \\
\hline Outer rotor radius $\left(\mathrm{D}_{\mathrm{r}}\right)$ & $5193.2[\mathrm{~mm}]$ & $5160.2[\mathrm{~mm}]$ \\
\hline Cogging torque & $240[\mathrm{KN}]$ & $155[\mathrm{KN}]$ \\
\hline Back EMF amplitude & $15.211[\mathrm{Kv}]$ & $11.784[\mathrm{Kv}]$ \\
\hline
\end{tabular}




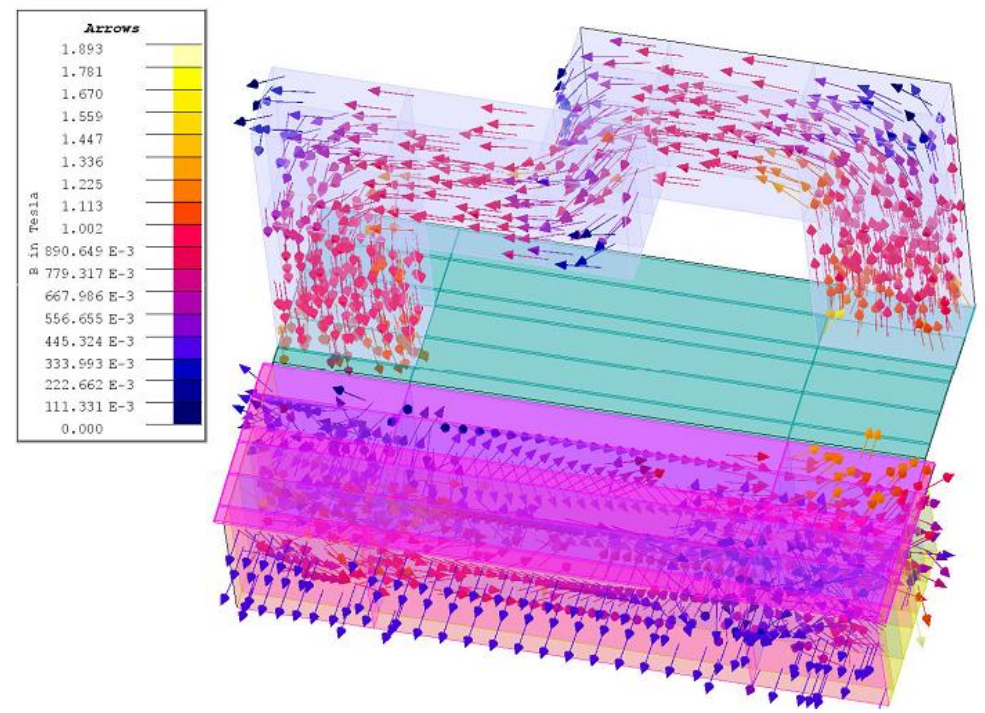

(a)
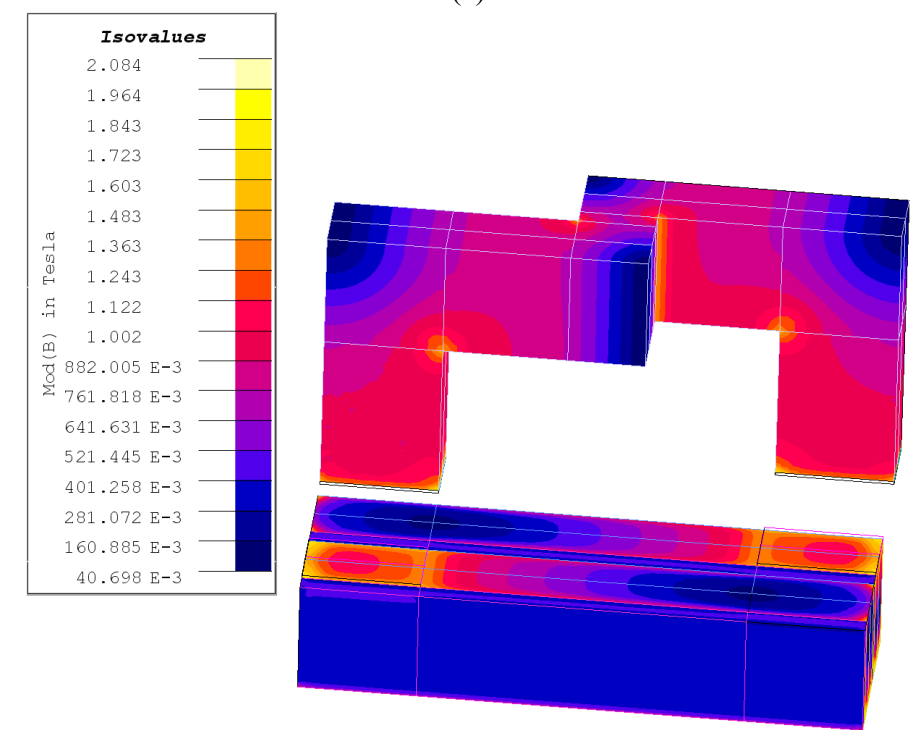

(b)
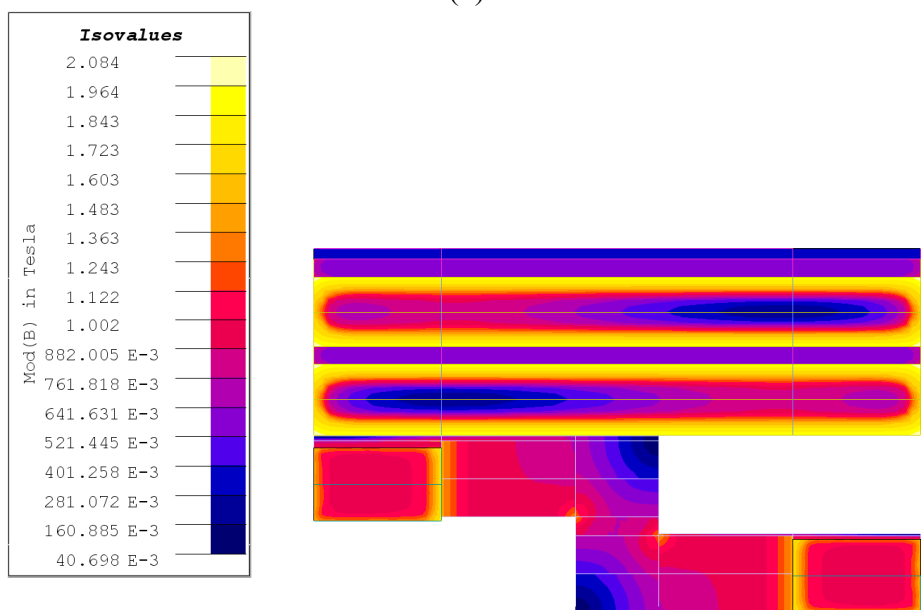

(c)

Figure 19. Flux lines and flux density of one pole - one phase of TFPM generator (a) Distribution of flux and flux lines (b) Isovalues diagram of flux density (c) Isovalues diagram of flux density from another view 


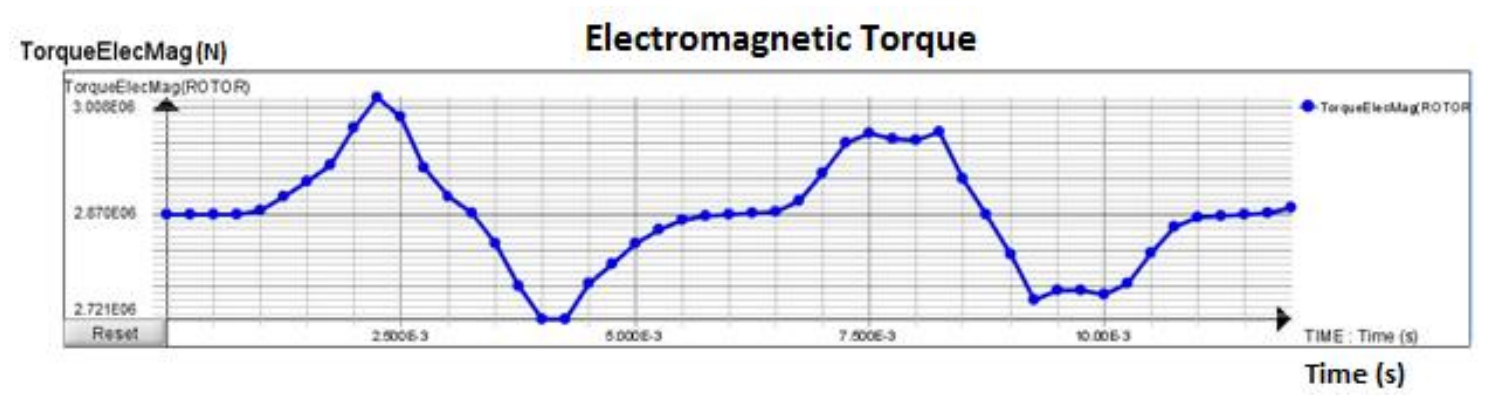

Figure 20. Electromagnetic torque of the TFPM machine for one phase.

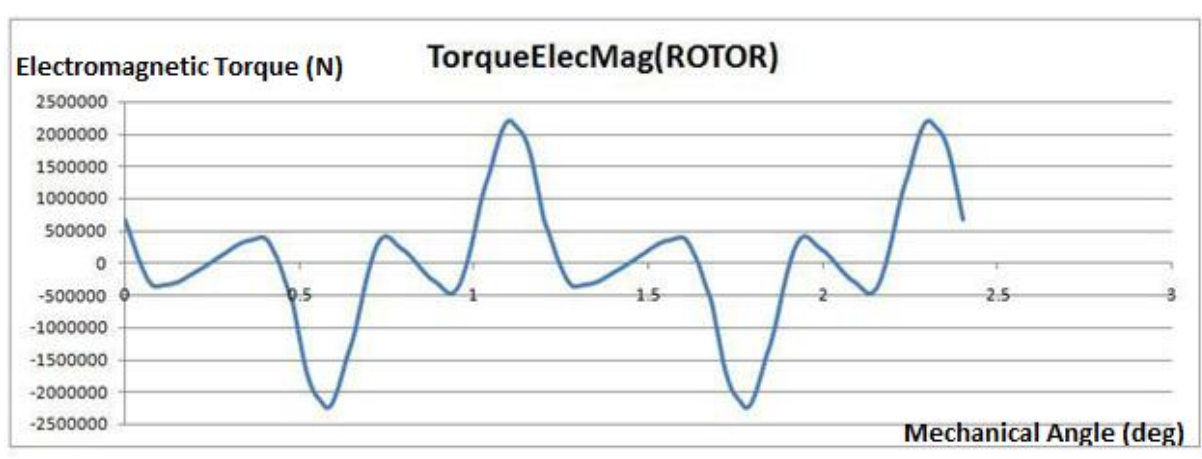

(a)

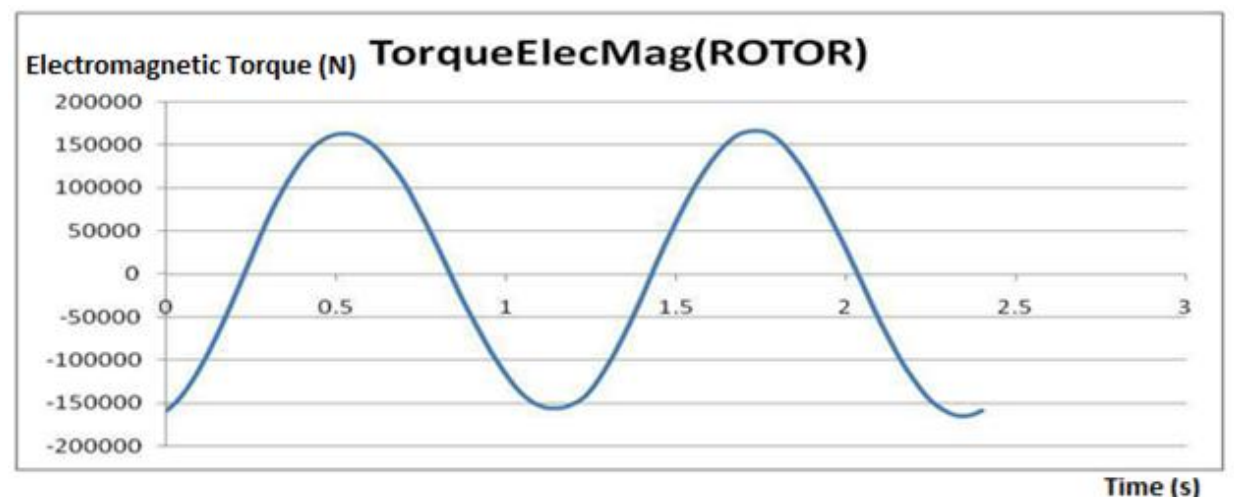

(b)

Figure 21. Cogging torque of simulated TFPM generator: (a) By primary values (b) By optimal values obtained from the flowchart

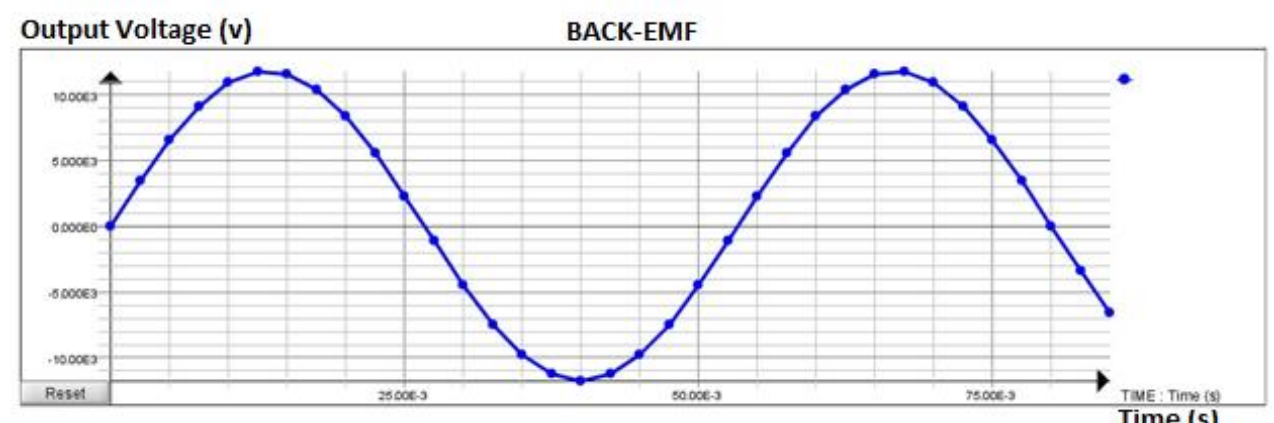

Figure 22. Extracted back EMF for one phase of simulated TFPM generator 


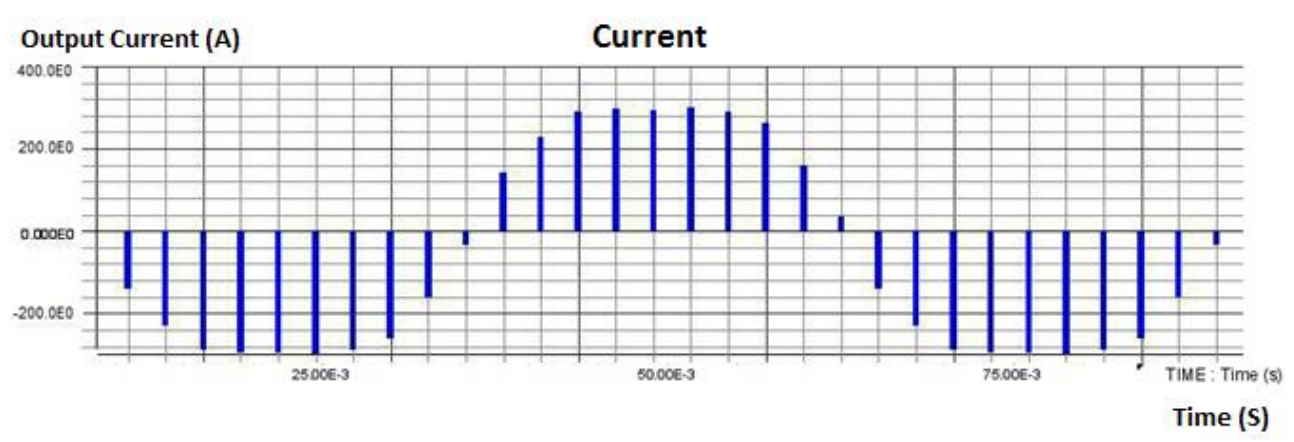

Figure 23. The output current per phase of simulated TFPM generator

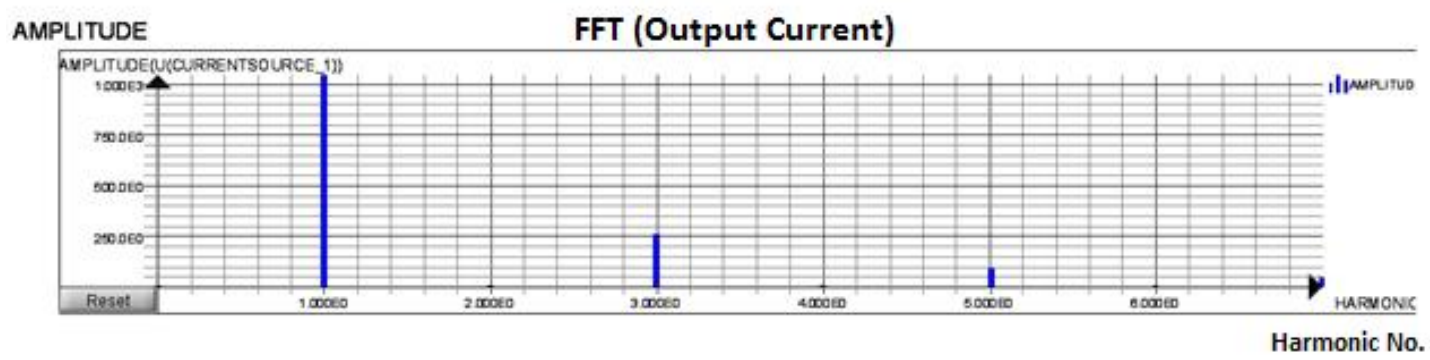

Figure 24. Harmonic Spectrum of generator's output current

\section{Conclusion}

In this paper a simple design method and optimization was introduced for a high power TFPMG applied in vertical axis direct drive wind turbine system by lowest possible amplitude of cogging torque and highest possible power factor, efficiency and power density. For this reason an optimum method called combined response surface methodology (RSM) and design of experiment and in order to extract the output values of generator and sensitivity analysis for improvement of design and optimization, a 3D-Finite element model was used. This method has high accuracy and gives us a better insight of generator performance and presents back EMF, cogging torque, flux density and FFT of this TFPMG. This study can help designers in design approach of such generators.

\section{References}

[1] Global Wind Report Annual Market Update 2013, Retrieved 23 April2013.

[2] M. C. Toklu, O. Uygun, "Location Selection for Wind Plant using AHP and Axiomatic Design in Fuzzy Environment", Periodicals of Engineering and Natural Sciences, vol. 6, no. 2, pp. 120-128, 2018.

[3] Polinder, H.; van der Pijl, F.F.A.; de Vilder, G.-J.; Tavner, P.J., "Comparison of direct-drive and geared generator concepts for wind turbines," Energy Conversion, IEEE Transactions on , vol.21, no.3, pp. 725,733 , Sept. 2006

[4] F. Valentin, T. Nica, K. Leban, E. Ritchie, "Direct Drive TFPM Wind Generator Analytical Design Optimized for inimum Active Mass Usage", The 8th International Symposium on Advanced Topics in Electrical Engineering, May 23-25, 2013, Bucharest, Romania.

[5] J. Soleimani, A. Ejlali, "Non-Conventional Electric Machines (Theory, Design \& Analysis)-Chapter 3", ISSN: 978-600-5714-18-0, NahrDanesh Publisher, Feb 2015, Tehran, Iran.

[6] J. Soleimani, A. Vahedi and A. Ejlali, "Study on Inner PMSM for HEV Traction Drive Application Considering Permanent Magnet Type and Temperature", Turkish Journal of Electrical Engineering and Computer Sciences, Volume 22, Issue 6, (2014). 
[7] J. Soleimani, A. Vahedi and S. M. Mirimani, "Inner Permanent Magnet Synchronous Machine Optimization for HEV Traction Drive Application in Order to Achieve Maximum Torque per Ampere", Iranian Journal of Electrical and Electronic Engineering, Vol.7 No.4, Dec 2011.

[8] R. Kerid, H. Bourouina, R. Yahiaoui, "Parameter identification of PMSM using EKF with temperature variation tracking in automotive applications", Periodicals of Engineering and Natural Sciences, vol. 6, no. 2, pp. 109-119, 2018.

[9] I. Boldea, "Variable Speed Generators-Chapter 11", ISBN 0- 8493-5715-2, CRS Press Taylor \& Francis, USA, 2007.

[10] F. Valentin, T. Nica, K. Leban, E. Ritchie, "A comparison between two optimized TFPM geometries for 5 MW direct-drive wind turbines," Advanced Topics in Electrical Engineering (ATEE), 2013 8th International Symposium on , vol., no., pp.1,6, 23-25 May 2013

[11] Deok-je Bang; Polinder, H.; Shrestha, G.; Ferreira, J.A., "Comparative design of radial and transverse flux PM generators for direct-drive wind turbines," Electrical Machines, 2008. ICEM 2008. 18th International Conference on , vol., no., pp.1,6, 6-9 Sept. 2008.

[12] D. Grassman, "Vertical axis wind turbine and generator therefore", United State Patent, Publication number: US8487470 B2 Jul 2013.

[13] M. R. Quddes, M. Sekino, H. Ohsaki, N. Kashima, S. Nagaya, "Electromagnetic Design Study of Transverse Flux Enhanced Type Superconducting Wind Turbine Generators", IEEE Trans. on Applied Supercunductivity, Vol. 21, No 3, Jun 2011.

[14] J. Soleimani, A. Ejlali, "Transverse Flux Generator Applied in Wind Turbine Systems", Technical Report, Azad University of Ilam, Iran, Jan 2016.

[15] J. Xie, D. Kang, B. C. Woo, J. Y. Lee, Z. H. Sha, S. D. Zhao, "Optimum Design of Transverse Flux Machine for High Contribution of Permanent Magnet to Torque Using Response Surface Methodology, Journal of Electrical Engineering \& Technology Vol. 7, No. 5, pp. 745 752, 2012.

[16] D. Hong, B. Woo , J. Chang and D. Kang, "Optimum Design of TFLM With Constraints for Weight Reduction Using Characteristic Function”, IEEE Trans. on Magnetics, Vol. 43, No. 4, April 2007.

[17] Y. Gong, W. Zheng, D. Zhang, J. Jiang, "Analysis of a Transverse Flux Machine with E-shaped Stator Using Three Dimensional Scalar Potential Finite Element Method" IEEE 6th International Power Electronics and Motion Control Conference (IPEMC), Wuhan, China, May 2009.

[18] D. Svechkarenko, "On Design and Analysis of a Novel Transverse Flux Generator for Direct-driven Wind Application", PhD Thesis in Electrical Eng. KTH Univ. 2010.

[19] G. Yang; D. Cheng; H. Zhang; B. Kou, "Bidirectional Cross-Linking Transverse Flux Permanent Magnet Synchronous Motor," Magnetics, IEEE Transactions on , vol.49, no.3, pp.1242,1248, March 2013.

[20] Dobzhanskyi, O.; Mendrela, E., Trzynadlowski, A.M., "Analysis of Leakage Flux Losses in the Transverse Flux Permanent Magnet Generator," Green Technologies Conference (IEEE-Green), 2011 IEEE, vol., no., pp.1,6, 14-15 April 2011.

[21] S. Komurcu, "Numerical Modelling of the In-Plane Loaded Homogenized Masonry Walls", Periodicals of Engineering and Natural Sciences, vol. 5, no. 3, pp. 314-321, 2017.

[22] O. Y. Bozkurt, I. C. Dai, O. Ozbek, "The Finite Element Analysis and Geometry Improvements of Some Structural Parts of a Diesel Forklift Truck", Periodicals of Engineering and Natural Sciences, vol. 5, no. 2, pp. 202-209, 2017.

[23] D.C. Montgomery, Design and Analysis of Experiments: 7th ed., New York: Wiley, 2008.

[24] A.I. Khuri and J.A. Cornell, Response Surfaces: Designs and Analyses: New York: Marcel Dekker, 1 996.

[25] C. Yuan, B.G. Liu and C.G. Chen, "Optimization of preparation process of hydroxypropyl- $\beta$ cyclodextrin by response surface methodology," in Proceedings of International Conference on Challenges in Environmental Science and Computer Engineering, Wuhan, China, pp.26-28, Mar. 2010. 
[26] S.I. Kim, J.P. Hong, Y.K. Kim, H. Nam and H.I. Cho, "Optimal design of slotless-type PMLSM considering multiple responses by response surface methodology," IEEE Trans. Magn., vol.42, no.4, pp.1 21 9-1 222, Apr. 2006.

[27] D.K. Hong, B.C. Woo and D.H. Kang, "Application of fractional factorial design for improving performance of $60 \mathrm{~W}$ transverse flux linear motor," J. Appl. Phys., vol.1 03, no.7, pp. 07F1 20:1 -07F1 20:3, Mar. 2008.

[28] B. Duraković, H. Bašić, "Continuous Quality Improvement in Textile Processing by Statistical Process Control Tools: A Case Study of Medium-Sized Company", Periodicals of Engineering and Natural Sciences, vol. 1, no. 1, pp. 36-46, 2013.

[29] B. Duraković, "Design of Experiments Application, Concepts, Examples: State of the Art", Periodicals of Engineering and Natural Sciences, vol. 5, no. 3, pp. 421-439, 2017. 